\title{
AGENDA NEOLIBERAL E A POLÍTICA PÚBLICA PARA O ENSINO SUPERIOR NOS ANOS 90
}

\section{Neoliberal Agenda and the Public Politics for Superior Education in Years 90}

Cristina Helena Almeida de Carvalho ${ }^{1}$

\section{Resumo}

Este texto tem como objetivo discutir a relação entre a agenda neoliberal e a implementação da política pública para o ensino superior no Brasil nos anos 90. A hipótese central é que apesar dos constrangimentos de ordem econômica e política, esta política não foi resultado exclusivo da intervenção externa. O Banco Mundial é um ator que, apesar de amplos recursos de poder, não consegue se impor por completo à agenda governamental e ao processo decisório. Na primeira parte, o texto pretende expor os principais pressupostos teóricos da agenda neoliberal. Em seguida, procura estruturar o ambiente, no qual o ensino superior se insere, para compreender quais as opções, as restrições e as motivações de mudança ou continuidade da política pública. Na última parte, a investigação segue para essa política, de forma a traçar um paralelo entre seus elementos constitutivos e as recomendações do Banco Mundial. A intenção é examinar semelhanças e divergências entre a agenda govemamental e a agenda sistêmica neoliberal.

Palavras-chave: Neoliberalismo; Política pública; Banco Mundial.

Doutoranda em Economia Aplicada pelo Instituto de Economia da Universidade Estadual de Campinas (UNICAMP). Bolsista do CNPq. E-mail: crishele@eco.unicamp.br 


\section{Abstract}

This texthas as objective to argue the relation between the neoliberal agenda and the implementation of the public politics for superior education in Brazil in years 90. The central hypothesis is that despite the constants of economic order and politics, this politics was not resulted exclusive of the extemal intervention. The World Bank is an actor who, although ample resources of being able, do not obtain to impose themselves for complete to the governmental agenda and the powerto decide process. In the first part, the textintends to display the main ones estimated theoreticians of the neoliberal agenda. After that, it looks for to structuralize the environment, in which superioreducation if inserts, to understand which the options, the restrictions and the motivations of change or continuity of the public politics. In the last part, the inquiry follows for this politics, of form to trace a parallel between its constituent elements and the recommendations of the World Bank. The intention is to examine similarities and divergences between the governmental agenda and the neoliberal sistêmica agenda.

Keywords: Neoliberalism; Public politics; World Bank.

\section{Introdução}

Educação e desenvolvimento. Este tem sido, de forma inequívoca, um dos temas mais importantes nos últimos 40 anos nas ciências sociais. Seja na economia ou na sociologia, os vínculos e as interações entre educação e desenvolvimento aparecem sob as mais diversas formas. No que se refere ao ensino superior, o tema tem sido abordado pelos diversos papéis, aspectos e atribuições que ele tem tido ao longo do tempo. Os diversos enfoques percorrem desde as suas contribuições para o desenvolvimento econômico da Nação; seu papel como investimento na linha da teoria do capital humano; como fator de redução das desigualdades sociais e promotor de ascensão social; até o caráter de bem público ou mercadoria/serviço regulado pelo mercado.

Um aspecto sobre o ensino superior que merece atenção é o da política pública. ${ }^{2}$ Em primeiro lugar, porque tem sido objeto de reflexão de governos, no Brasil e alhures. Em segundo lugar, porque em nossa história recente, tem sido alvo de acalorado debate e de formas distintas de atuação do Estado. No que tange a ação pública, a diversidade de interesses envolvi-

2 Política Pública é entendida neste trabalho como um conjunto de medidas que conformam um determinado programa de ação governamental, que procura responder a demandas de grupos de interesse. Sob o enfoque concreto, implica considerar os recursos de poder que operam na sua definição e que têm nas instituições do Estado, sobretudo na máquina governamental, o seu principal referente. (Azevedo apud Gisi, 2003). Neste quadro analítico, a política educacional traduz-se em política pública de corte social. 
dos e a magnitude dos recursos dispensados pelos diversos atores em torno desta questão realçam sua importância como objeto de investigação. ${ }^{3}$

Nos anos 90, todo o espectro de políticas sociais e econômicas esteve sob a influência da chamada Agenda Neoliberal. ${ }^{4} \mathrm{O}$ conjunto de propostas assumiu um caráter abrangente, com implicações para além das fronteiras nacionais, o que confere especificidade à década. Daí a relevância de uma investigação que procure apreender a singularidade deste momento histórico, no que concerne à política pública para o ensino superior.

O principal objetivo do trabalho é compreender a relação complexa e dinâmica que se estabelece no interior das decisões de política pública para o ensino superior nesse período. A idéia é esquadrinhar os múltiplos condicionantes do processo decisónio - interação de atores, interesses e estratégias - a fim de captar o caminho entre o processo de formulação de alternativas e a implementação da política educacional.

A perspectiva analítica procura entender o processo decisório como produto da ação desigual dos atores, à luz das questões da agenda neoliberal, cujos resultados se manifestam por meio das alterações no quadro legislativo e nos mecanismos de incentivo e financiamento do ensino superior. ${ }^{5} \mathrm{~A}$ formulação e a implementação das políticas públicas são duas dimensões do processo decisório, no qual se revela o jogo estratégico de poder, os acordos, o consenso e a acomodação de interesses diversos.

3 Os atores so ciais ou políticos “... são sujeitos dotados da capacidade de ação, determinada pela disponibilidade de recursos institucionais, tecnológicos, gerenciais, financeiros e políticoideológicos". (Castro, 1997, p. 26). São "todos aqueles dotados de capacidade de articular interesses, formalizar reivindicações e convertê-las em iniciativas, prescrever soluções, promover sua solução ou impedir que as decisões sejam implementadas" (Martins apud Tápia, 1993, p. 20).

4 A agenda governamental é entendida como uma lista de problemas, assuntos e temas que chamam à atenção do govemo e dos participantes visíveis (Presidente, altos burocratas, congressistas e outros) que atuam junto ao govemo (Kingdon, 1995). Mas, é importante evidenciar a distinção estabelecida por Cobb e Elder (1995) entre a agenda sistêmica e a govemamental. A primeira consiste nas questões que são comumente percebidas pelos membros da comunidade política como merecedoras da atenção pública e como assuntos incluídos na jurisdição legítima da autoridade govemamental existente. A segunda, também denominada de agenda institucional ou formal, é entendida como aquele conjunto de pontos explícitos elevados à consideração ativa e séria dos decision-makers. Os policy-markers participam da construção de ambas, entretanto, a natureza é substancialmente diferente. A agenda sistêmica é composta nitidamente de pontos abstratos e gerais, enquanto que a governamental tende a ser mais específica, concreta e limitada a um certo número de questões em pauta.

5 O estudo procura proporcionar uma visão dinâmica e abrangente da política pública para 0 ensino superior. A análise documental mais aprofundada da legislação pertinente e os documentos oficiais do Banco Mundial não fazem parte do escopo deste texto. Este trabalho será desenvolvido em textos posteriores. 
A hipótese central é que apesar dos constrangimentos de ordem econômica e política, dados pela agenda neoliberal, a política pública direcionada ao ensino superior não foi resultado exclusivo da intervenção dos organismos multilaterais. As recomendações do Banco Mundial (BIRD) influenciaram, parcialmente, a política pública para o setor. Esta instituição é um ator que, apesar de amplos recursos de poder, não consegue, de forma isolada, impor-se completamente à agenda governamental, muito menos ao processo decisório, pois necessita do respaldo e do consentimento dos atores internos.

Na primeira parte, o texto pretende expor os principais pressupostos teóricos da agenda neoliberal. Em seguida, procura esquadrinhar o contexto socioeconômico e político brasileiro específico dos anos 90 . A intenção é estruturar o ambiente no qual o ensino superior se insere, para compreender quais as opções, as restrições e as motivações de mudança ou continuidade da política pública. Na última parte, a investigação segue para esta política, de forma a traçar um paralelo entre seus elementos constitutivos e as recomendações do Banco Mundial. Pretende-se examinar as semelhanças e divergências entre a agenda governamental e a agenda sistêmica neoliberal.

\section{Pressupostos da Agenda Neoliberal}

O neoliberalismo surgiu após a $2^{\text {a }}$ Guerra Mundial, na região da Europa e da América do Norte, nos países capitalistas centrais. Pode-se dizer que sua origem esteve relacionada ao texto o "Caminho da Servidão", de Friedrich Hayek, de 1944, uma espécie de reação teórica e política contra o Estado intervencionista e de bem-estar. A promoção do livre comércio, a estabilização macroeconômica e as reformas estruturais deram origem ao General Agreement on Trade and Tariffs (GATT) e as instituições gêmeas que nasceram das deliberações de Bretton Woods: o Banco Mundial em 1945 e o Fundo Monetário Internacional em 1946.

O ideário passou a ganhar notoriedade com a crise do modelo econômico, em 1973, na qual se combinaram baixas taxas de crescimento com altas taxas de inflação. Em 1979, foi eleito, na Inglaterra, o primeiro governo disposto a implementar o programa neoliberal seguido por outros países avançados na década de 1980.

A crítica iniciou-se pelo ataque ao Estado de Bem-Estar do pós-guerra e sua concepção keynesiana de intervenção pública na economia. A tese principal é a do Estado mínimo, na qual o mercado é o mais eficiente mecanismo de alocação de recursos. O esvaziamento do Estado deve ser feito em seu tamanho, papel e funções. 
No mesmo período, nos países centrais, a chamada "terceira revolução industrial" - traduzida pelas inovações tecnológicas que tornaram a produção flexível - transformou as relações industriais, o sistema laboral e 0 gerenciamento empresarial. A liberalização e a expansão dos mercados financeiros foram outra faceta deste processo, no qual a supremacia dos mercados de capitais vem se impondo ao tradicional sistema de crédito bancário. Como define Cardoso de Mello, de forma eloqüente,

...esse extraordinário poder econômico privado - das empresas produtivas e das organizações financeiras - se lança de maneira hostil contra as políticas nacionais de proteção social, de um lado, e, por outro, contra as políticas nacionais de preservação dos sistemas industriais voltadas para o mercado interno, transformando os Estados Nacionais em reféns das políticas do Grande Capital. (1997, p. 20).

As mudanças nas relações de trabalho e as diferentes formas de inserção, bem como a constituição da "macroestrutura financeira"6 e sua autonomização ${ }^{7}$ minaram as bases de sustentação do Estado de Proteção Social, à medida que a estrutura calcava-se no emprego formal.

Os países avançados, a partir dos anos setenta, passaram a questionar seus modelos de proteção social, no que tange aos excessivos gastos e a pressão destes sobre o orçamento público. Combinado a isso, os resultados do sucesso do Estado de Bem-Estar trouxeram novas questões: 0 envelhecimento populacional e as conquistas dos direitos sexuais e de cidadania ocasionaram novas pressões sobre os gastos sociais.

$\mathrm{O}$ ajuste econômico, tema central do neoliberalismo, traduzido pelo controle das contas públicas, pretendia redirecionar a estrutura de proteção social para políticas focalizadas e de combate à pobreza. ${ }^{8}$

De modo geral, e com ampla diferenciação entre os países, as medidas adotadas foram: controle na emissão de moeda; aumento das taxas de juros; queda na incidência de impostos sobre altos rendimentos; extinção de

6 'Trata-se de uma configuração de caráter misto, público-privado, constituída pela monumental massa de recurso, hoje concentrada nas mãos de bancos centrais, grandes bancos internacionais, fundos de investimento, companhias de seguro, corporações multinacionais, fundos de pensão e proprietários de grandes fortunas." (Martins, 1996, p.7).

7 "Na verdade, a esfera financeira se autonomizou. Ela passou a ser um campo de valorização independente, no qual se desenvolve a forma mais fetichizada de manifestação do capital: é o dinheiro gerando mais dinheiro, diretamente, sem passar pelos processos de produção de mercadorias e de_comercialização das mercadorias produzidas." (Ibidem, p. 8).

${ }^{8}$ Mesmo nos casos "exitosos" de ajuste e estabilização de curto prazo, o crescimento econômico resultante produz um constante aumento da pobreza, da desigualdade e da exclusão social (Borón, 2000). 
controle sobre fluxos financeiros; política de corte nos gastos sociais, e, por fim, a privatização das empresas estatais. (Anderson, 2000).

Nos países latino-americanos, no bojo do receituário neoliberal, os ajustes macroeconômicos eram acompanhados de prescrições de reformas dos "débeis" sistemas de proteção social, orientados para a privatização, ${ }^{9}$ descentralização, ${ }^{10}$ focalização $0^{11}$ e programas (fundos) sociais de emergência (DRAIBE, 1993).

As mudanças na área social apoiaram-se em três grupos de justificativas. Em primeiro lugar, nos ajustamentos fiscais da primeira metade dos anos 80 exigia-se maior eficiência e adequação aos objetivos macroeconômicos, principalmente, os de estabilização e de natureza fiscal, cuja face mais visível foi o corte no gasto social. Em seguida, previa-se redirecionar este gasto para a população mais vulnerável aos impactos do ajustamento recessivo sobre emprego, renda e redução dos serviços sociais. A focalização do gasto e os fundos sociais de emergência e os programas compensatórios constituíram 0 núcleo duro da estratégia de reforma. Por fim, o gasto social haveria de priorizar ações básicas de saúde, nutrição e, principalmente, os programas de caráter produtivo, o investimento em "capital humano" (DRAIBE, 1997).

Uma das principais inovações institucionais ocorridas no financiamento do gasto social latino-americano, nos anos 80/90, baseou-se na criação de fundos sociais, recomendados e concebidos como instrumento transitório e emergencial dos governos para enfrentar os agudos problemas sociais derivados das crises e das políticas de ajustamento, em particular seus impactos negativos sobre o emprego, os salários e o gasto público social (WURGAFT apud DRAIBE, 1997).

9 A privatização "...entendida como deslocara produção de bens e serviços públicos para o setor privado lucrativo foi apresentada como uma resposta que alivia a crise fiscal, evita irracionalidade no uso de recursos induzida pela gratuidade de certos serviços públicos e aumenta a progressividade do gasto público ao evitar que os setores de maior poder se apropriem de benefícios não proporcionais (maiores) à contribuição que realizam para financia-los" (Issuani apud Draibe, 1993, p. 97). Isto se dá, também, pelo deslocamento da produção e/ou da distribuição de bens e serviços públicos ao setor privado não-lucrativo, composto por associações de filantropia e organizações comunitárias, ou as novas formas de organizações não-governamentais.

10 A descentralização é concebida "como um modo de aumentara eficiência e a eficácia do gasto, já que aproxima problemas e gestão. Argumenta-se ainda que, com a descentralização, aumentam as possibilidades de interação, no nível local, dos recursos públicos e dos nãogovernamentais, para o financiamento das atividades sociais. Enfim, amplia-se a utilização de formas alternativas de produção e operação dos serviços, mais facilmente organizadas nas esferas municipais." (Ibidem).

${ }^{11}$ A focalização significa "o direcionamento do gasto social a programas e a públicos-alvo específicos, seletivamente escolhidos pela sua maior necessidade e urgência." (Ibidem) 
Estes fundos, na sua maioria, promovidos e apoiados pelo Banco Mundial, tinham como diagnóstico as deficiências nos quesitos eficiência e efetividade dos programas sociais e a incapacidade institucional de resposta ágil à precariedade das condições sociais. Os fundos tornaram-se instrumentos eficazes na captação de recursos externos - doações ou créditos - destinados a apoiar programas sociais de emergência focalizados nos grupos dos mais pobres entre os pobres.

Dados os pressupostos da agenda neoliberal, em especial para a Aménca Latina, este trabalho pretende delinear, na próxima seção, o ambiente político, econômico e social brasileiro no qual o ensino superior encontrava-se inserido.

\section{Ambiente sociopolítico e econômico}

No Brasil, a crise econômica do início dos anos 80 decorrente da subida das taxas de juros internacionais e da segunda crise petrolífera reverteu o fluxo de divisas em direção aos países centrais. O ajuste promovido pela política econômica repercutiu na queda dos salários reais; promoveu a estatização da dívida externa; realizou sucessivas desvalorizações cambiais e elevou as taxas de juros domésticas.

O rompimento do padrão de financiamento da economia - sedimentado nos recursos externos - foi seguido pela ruptura do esquema de financiamento do setor público. A situação financeira estatal agravou-se, devido aos efeitos das desvalorizações cambiais sobre a dívida externa; às conseqüências da recessão e da aceleração do processo inflacionário sobre a arrecadação fiscal e as receitas das empresas estatais e pelo impacto das altas taxas de juros sobre a dívida mobiliária e bancária.

Com o fim do regime autoritário, distinguiam-se dois movimentos estruturais e antagônicos entre as forças progressistas e conservadoras e suas respectivas atuações nas arenas decisórias do Poder Executivo Federal (1985/ 86) e na Assembléia Nacional Constituinte (1987/88). A Constituição Federal de 1988 representa a imagem dessa contradição: combinam-se avanços no caráter formal às distorções na regulamentação das conquistas sociais.

O contexto político de reorganização da sociedade civil e a reconstrução dos partidos políticos - no contexto de esgotamento do regime militar - permitiram a constituição de uma agenda reformista formada pela aliança entre o PMDB e os dissidentes do PDS. Em essência, esta agenda fazia crítica severa ao caráter excludente da política social, explicitando, na fala dos atores políticos, a necessidade do resgate da dívida social. Os princípios essenciais eram: os direitos relacionados à cidadania; a solidariedade; a universalização e a descentralização. 
Este último, que se tornou ícone da agenda neoliberal, assumiu característica diferenciada no Brasil. A aversão ao regime militar e a centralização exacerbada que com ele se confundia teve como reação a associação direta entre a descentralização e a democracia. A descentralização financeira e administrativa para os estados e municípios passou a ser a grande bandeira contra a exclusão social. A reforma tributária deveria ser direcionada à descentralização de recursos em benefício dos municípios, mais próximos do controle social.

Em resumo, o movimento da política social brasileira, em meados da década de 80, em direção ao progresso na questão da cidadania, foi na contramão do avanço mundial dos princípios neoliberais. Buscavam-se mecanismos superiores de integração e de universalização das políticas públicas.

Mais intensamente nos anos 90, o processo de globalização espraiase pela periferia endividada, tornando a integração brasileira inevitável. ${ }^{12}$

No início da década, com a primeira eleição direta para Presidência da República, elege-se Fernando Collor. O voluntarismo individual e excesso de poder discricionário impossibilitaram a cooperação entre os Poderes Executivo e Legislativo e instituíram comportamentos clientelistas de favorecimento entre o governo e a iniciativa privada.

A partir de um plano de estabilização monetária de profundo enxugamento da liquidez, a política econômica voltou-se à abertura indiscriminada das barreiras tarifárias e o início do processo de privatização das empresas estatais. Em outras palavras, a adoção da agenda neoliberal de redução do papel do Estado foi acompanhada da desarticulação de parte significativa das cadeias produtivas, com rompimento do tripé que sustentava a estrutura econômica. A participação do capital nacional foi reduzida, o setor estatal privatizado e atribui-se maior participação relativa ao capital estrangeiro.

O aparato de proteção social transformou-se em espaço de negócios privados, com o encolhimento da máquina administrativa e a perda de ação de setores da burocracia estatal mais qualificada. A formulação de uma nova agenda de reformas - com a revisão constitucional em 1993 e a mobilização do Executivo Federal para obstruir a consumação de novos direitos constitucionais na legislação complementar - foi suspensa com o impeachment de Collor (FAGNANI, 1999).

Este processo de inserção subordinada foi aprofundado a partir do Plano Real, em 1994. A aliança conservadora de sustentação política do governo Fernando Henrique Cardoso tentou promover consenso em torno da agen-

12 É importante salientar que é possível estabelecer graus de autonomia relativa - institucional e política - à estratégia neoliberal, de acordo com a forma de inserção no jogo de forças das economias nacionais. 
da de reformas, mas, no jogo político, devido à resistência das correntes de esquerda, algumas não foram concretizadas. O processo de privatização das empresas estatais, um dos ícones da agenda sistêmica, foi implementado, de forma apressada e com favorecimentos aos grupos multinacionais e locais.

Na esfera econômica, prevaleceu a lógica neoliberal nos dois mandatos do FHC: crescentes superávits orçamentários, crescimento medíocre e deterioração do mercado de trabalho com taxas de desemprego em ascensão.

No que tange à política de ensino superior, a tônica foi o aprofundamento, sob diversas formas, da privatização. Os princípios produtivistas e 0 corte nos gastos públicos foram acompanhados do discurso de justiça social. A seguir, o texto pretende abordar estes elementos constitutivos com melhor clareza.

\section{Política de Ensino Superior no Brasil}

A influência externa na educação superior brasileira teve seus primórdios nos anos sessenta. No bojo do padrão de relações internacionais, o principal veículo dos fundos e de execução da Aliança para o Progresso foi a Agency for International Development (AID). A USAID, como ficou conhecida, tornou-se o principal financiador do Brasil, fornecendo $80 \%$ do capital líquido, de longo prazo, que entrou entre 1964 e 1967 (Skidmore apud Carvalho, 2002). Essa agência passou a prestar assistência técnica e cooperação financeira em prol da reorganização do sistema educacional brasileiro, por uma série de acordos com o MEC. ${ }^{13}$

A urgência na reestruturação do ensino superior foi emblemática. No bojo das sugestões dos especialistas da USAID, encontrava-se, de forma inequívoca, a racionalização das estruturas administrativas para reduzir a capacidade ociosa e os gargalos do sistema, bem como o estímulo às carreiras técnicas, subjacente à abordagem do investimento em capital humano. Estas questões tiveram papel relevante nos rumos da Reforma Universitária brasileira desencadeada no final da década (CARVALHO, 2002).

Nos anos noventa, novamente, uma agência multilateral, na figura do Banco Mundial (BIRD), passou a exercer influência efetiva na política educacional. Nos documentos oficiais apontava-se a necessidade de nova reforma, no sentido de dar racionalidade e eficiência ao sistema, princípios fundamentais da agenda governamental desde os anos 60 .

13 Houve uma rápida proliferação de contratos com a USAID nos campos da educação agrícola, de reforma agrária, produção pesqueira, erradicação da malária, produção de livros didáticos, treinamento de líderes trabalhistas e expansão de mercados de capital. 
A modemização administrativa associada aos princípios neoliberais daria nova roupagem à visão eficientista e produtivista. Novos conceitos foram introduzidos à agenda de reformas: avaliação, autonomia universitária, diversificação, flexibilização, privatização. ${ }^{14}$ Uma das críticas essenciais é a ineficiência da universidade pública e sua inadequação ao mercado de trabalho, resultado do modelo concebido pela Reforma Universitária de 1968, que estabeleceu a indissociabilidade entre ensino, pesquisa e extensão.

O processo de reforma do ensino superior em curso no Brasil revela um modelo concebido em meados da década de 1980, expresso no Grupo Executivo para a Reformulação da Educação Superior (GERES). A continuidade das propostas dos atores govemamentais pode ser compreendida como produto, também, da permanência de dirigentes e quadros técnicos, o que permite traçar um elemento de continuidade, no Ministério da Educação, entre os govemos de José Sarney, Fernando Collor, Itamar Franco e Femando Henrique Cardoso (Cunha, 2003). ${ }^{15}$

No projeto político do governo Collor, pautado no discurso de modernização, caberia às instituições de ensino superior a formação de recursos humanos para o mercado de trabalho e a aproximação entre a universidade e o mercado. Para superar os obstáculos identificados, a estratégia deveria seguir em cinco linhas: ampliação do acesso; respeito à autonomia universitária; maior estímulo ao desenvolvimento de pesquisas entre universidades e empresas; ampliação dos programas de pós-graduação; e capacitação e valonização dos profissionais de educação.

Em contraste, com a fala oficial, a práxis revelou-se o oposto do pretendido. A participação das despesas com pessoal em relação aos gastos com as IFES foi reduzida. Em conjuntura de inflação elevada, a estratégia era retardar a liberação de recursos destinados à rubrica "Outros Custeios e Capital" e descumprir sistematicamente o preceito constitucional. ${ }^{16}$ (VELLOSO apud CORBUCCI, 2002).

Neste período, houve baixo crescimento das matrículas privadas, inclusive com queda absoluta em 1992, situação somente observada na transição do regime ditatorial para o democrático, mais especificamente, em 1984 (Gráfico 1). Este movimento acompanhou a trajetória da economia brasileira, como é possível verificar na evolução do PIB. (Gráfico 3).

14 Os documentos enfatizam a necessidade de máxima diversificação institucional e flexibilização curricular. A ênfase direciona-se à criação de cursos de curta duração e à distância, de forma a substituir o modelo de universidade que associa ensino e pesquisa. No geral, instituições privadas, de qualidade duvidosa, têm oferecido vagas ociosas em cursos de curta duração pós-secundários (Sguissardi, 2000).

15 De acordo com Cunha (2003), a estratégia governamental tem sido o enfrentamento parcial de problemas e de adversários.

16 O artigo 212 da Constituição Federal de 1988 estabeleceu a vinculação mínima de 18\% da receita resultante de impostos arrecadados pela União ao setor educacional. 


\section{Gráfico 1 - Evolução das matrículas no ensino superior}

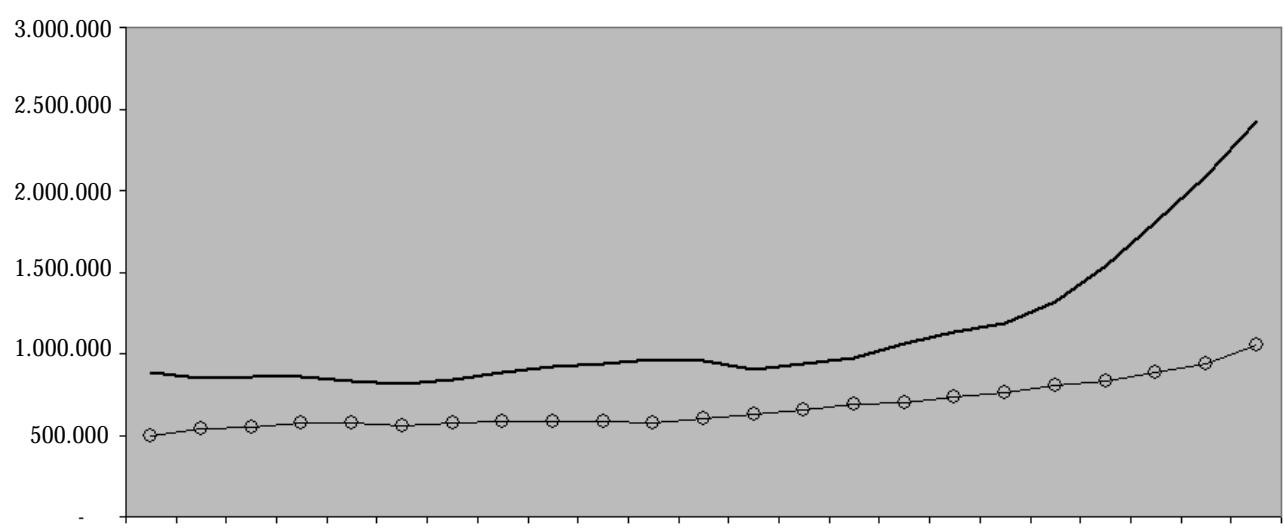

19801981198219831984198519861987198819891990199119921993199419951996199719981999200020012002

Fonte INEP/MEC

O fenômeno pode ser explicado devido à perda de poder aquisitivo da classe média combinada ao confisco das poupanças privadas, gerando incerteza por parte da demanda por ensino superior (Gráfico 2). A taxa de desemprego em ascensão e o recrudescimento do processo inflacionário após o fracasso do plano de estabilização contribuíram para agravar o quadro de incerteza (Gráfico 3).

\section{Gráfico 2 - Rendimentomédio do trabalho principal - RMs (deflator: INPC)}

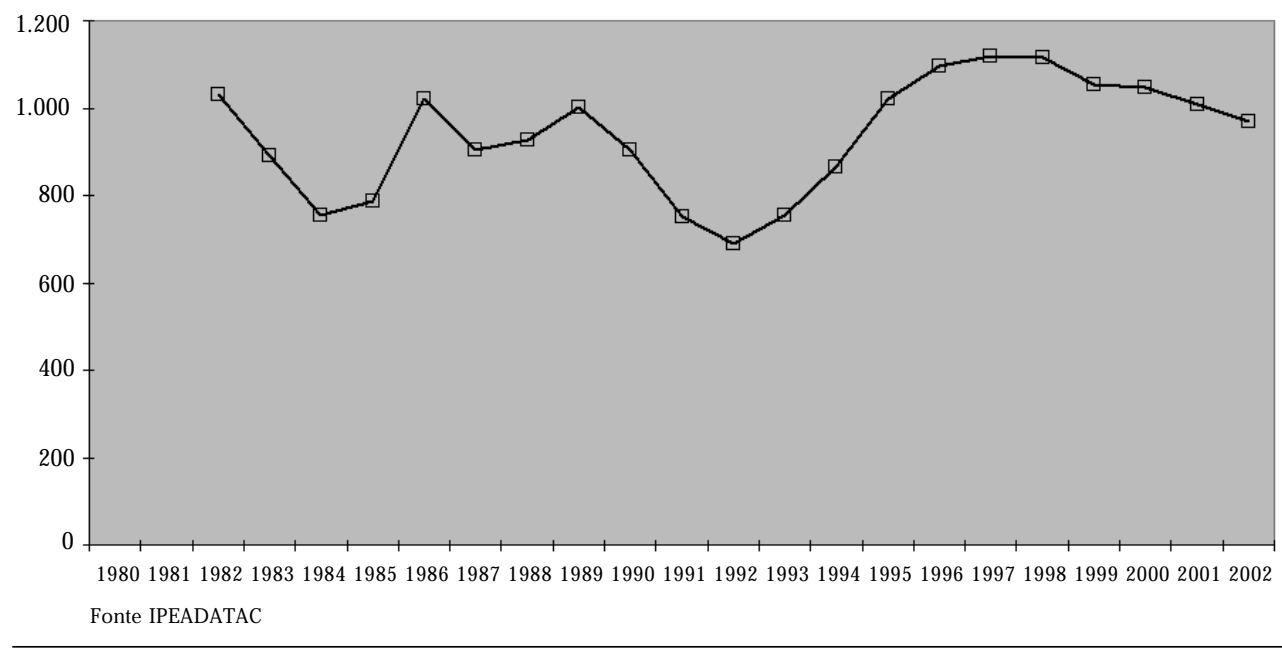

Diálogo Educ., Curitiba, v. 7, n. 21, p.83-101, maio./ago. 2007. 
Durante o curto espaço de tempo do governo Itamar, destacou-se a disputa acirrada de poder entre o MEC e o Conselho Federal de Educação (CFE), que resultou a extinção deste último e sua substituição pelo Conselho Nacional de Educação (CNE), este órgão com menor poder decisório e função mais consultiva e de assessoria do MEC. Não houve mudanças significativas na política pública no período.

\section{Gráfico 3 - Evolução da Taxa de Crescimento do PIB e da Taxa de Desemprego no Brasil}

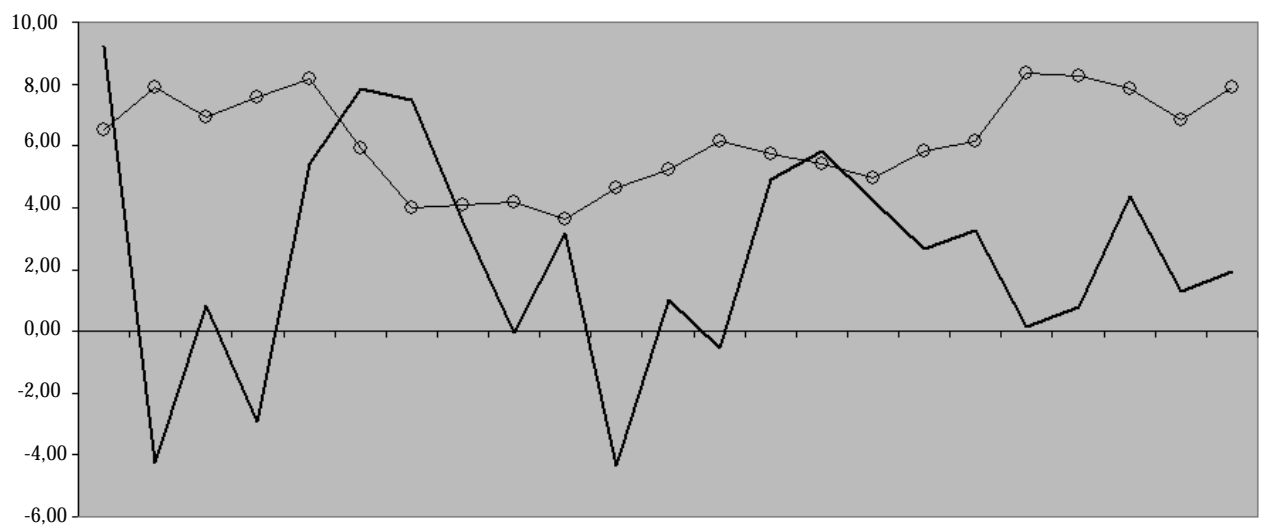

19801981198219831984198519861987198819891990199119921993199419951996199719981999200020012002

$\multimap$ Taxa de desemprego - aberto - referência: 30 dias - RMs — PIB - val. real atual (\%)

Fonte: IPEADATA

No governo Fernando Henrique Cardoso, a Lei de Diretrizes e Bases da Educação Nacional (LDB) sancionada em 1996, após oito anos de longa tramitação no Congresso Nacional, foi a principal iniciativa legislativa. A interação dos atores políticos e os conflitos de interesses produziram um texto legal que, em linhas gerais, combinava a coexistência de instituições públicas e privadas de ensino e a manutenção da gratuidade do ensino público em estabelecimentos oficiais.

A política para o ensino superior adquiriu centralidade e algumas propostas do governo Collor foram retomadas. O Plano Plurianual 1996/99 apresentava dois pressupostos: a importância do setor para a melhoria da qualidade do ensino e a formação de recursos humanos qualificados com vistas à modernização do país. O documento previa ainda a criação de um sistema de avaliação da qualidade dos serviços ofertados pela iniciativa privada - que se concretizou por meio do Exame Nacional de Cursos (ENC). A formação de um corpo técnico apto para atender às exigências do desenvolvi- 
mento tecnológico e o estreitamento dos laços entre universidade-empresa também foram pontos centrais.

A iniciativa do poder executivo central de formulação do projeto de autonomia apresentado pelo Ministério da Administração e da Reforma do Estado (MARE), em 1995, parece mostrar pontos de contato entre as recomendações do Banco Mundial e a agenda governamental. Em linhas gerais, esse consistia em transformar o status jurídico das universidades públicas para organizações sociais, entidades públicas não estatais, fundações de direito privado ou sociedades civis sem fins lucrativos. A interação entre o Estado e estas organizações sociais se daria por meio de um contrato de gestão, no qual estariam previstos os serviços que seriam prestados, as metas a serem atingidas e os recursos financeiros que deveriam ser transferidos a cada ano, do governo para a organização. $O$ documento preconizava a adoção de um modelo de administração gerencial para as instituições públicas. ${ }^{17}$

Entretanto, a reação dos atores representantes da comunidade acadêmica ao projeto foi de tal monta, que a conversão das universidades de autarquias ou fundações em organizações sociais passou a ter caráter voluntário. Vale frisar que as três universidades paulistas autônomas permanecem autarquias estaduais. ${ }^{18}$

A política para o segmento público foi na direção do sucateamento, devido à redução drástica do financiamento do governo federal e à perda de docentes e funcionários técnico-administrativos, associados à compressão de salários. ${ }^{19}$ Os dados da tabela 1 são bastante ilustrativos.

O financiamento do ensino superior sofreu, de forma significativa, com a política macroeconômica. As universidades federais tiveram seus orçamentos reduzidos com repercussões nos gastos em custeio e investimento. 0 ajuste foi feito para compensar a ascensão de outras despesas correntes, tais como: o pagamento de inativos e pensionistas, as sentenças judiciais trabalhistas (precatórios) e os hospitais universitários.

17 Esta proposta de reforma para o sistema federal ancorou-se em quatro características fundamentais: privatização, diferenciação, flexibilização e descentralização das estruturas e centralização de controle das IFES. (Silva Júnior e Sguissardi, 1997)

18 No caso das três universidades estaduais paulistas, que gozam de autonomia orçamentária, administrativa e financeira implantada em 1989, o financiamento governamental baseia-se em percentual fixo do ICMS. No entanto, estas são responsáveis por quase a totalidade da pesquisa científica produzida em São Paulo e, em grande parte, pela formação de mestres e doutores para o sistema público e privado, o que implica na reduzida capacidade de sustentação própria, face aos gastos elevados em ensino, pesquisa, ciência e tecnologia.

19 O pagamento de pessoal e encargos sociais inclui pessoal ativo e inativo, pensionistas, precatórios, salário-família. Em outras despesas correntes estão a aquisição de material de consumo, pagamento de serviços de terceiros, pagamento de água, luz, telefone, cópias, consertos de equipamentos e reparos em prédios. Os investimentos incluem a realização de obras, aquisição de equipamentos, material permanente, livros, etc. 


\section{Tabela1 - Recursos das IFES (1989 a 2002), todas as fontes de recursos Valores em R\$ milhões, a preços de janeiro de 2003 (IGP-DI/FGV)}

\begin{tabular}{c|c|c|c|c|c|c|c}
\hline Ano & $\begin{array}{l}\text { Pessoal } \\
\text { Encargos } \\
\text { Sociais }\end{array}$ & $\begin{array}{l}\text { Encargos } \\
\text { da dívida }\end{array}$ & $\begin{array}{l}\text { Outras } \\
\text { despesas } \\
\text { correntes }\end{array}$ & Investimentos & $\begin{array}{l}\text { Inversões } \\
\text { Financeiras }\end{array}$ & $\begin{array}{l}\text { Amortizações } \\
\text { da Dívida }\end{array}$ & Total \\
\hline 1989 & 12.035 & 2 & 1.260 & 374 & 0 & 1 & 13.672 \\
1990 & 9.197 & 2,7 & 1.383 & 543 & 2,7 & 3,6 & 11.132 \\
1991 & 7.023 & 4,5 & 1.288 & 442 & 3,1 & 1,4 & 8.762 \\
1992 & 6.129 & 4,2 & 1.372 & 412 & 2,1 & 1,6 & 7.921 \\
1993 & 7.749 & 3,2 & 1.855 & 669 & 4,6 & 1,4 & 10.282 \\
1994 & 9.573 & 3,3 & 2.171 & 741 & 14,2 & 2 & 12.505 \\
1995 & 10.883 & 3,1 & 2.076 & 440 & 7 & 2,1 & 13.411 \\
1996 & 9.700 & 3,7 & 2.110 & 267 & 1,7 & 1,5 & 12.084 \\
1997 & 9.658 & 2 & 2.002 & 204 & 0,3 & 3,7 & 11.870 \\
1998 & 9.531 & 1,2 & 2.042 & 87 & 0,1 & 1,3 & 11.663 \\
1999 & 9.869 & 0 & 1.456 & 89 & 0,1 & 0 & 11.414 \\
2000 & 9.240 & 0 & 1.391 & 129 & 0,2 & 0 & 10.760 \\
2001 & 8.409 & 0 & 1.334 & 104 & 0,1 & 0 & 9.847 \\
2002 & 8.819 & 0 & 1.122 & 69 & 2 & 0 & 10.012 \\
\hline
\end{tabular}

A queda da massa salarial a partir de 1995 foi resultado de uma política de recursos humanos que não proporcionou nenhum reajuste linear de salários em todo o período, além de impedir a abertura de concursos públicos para as vagas dos aposentados. A elevação de recursos em 1999 ocorreu devido à implementação da Gratificação de Estímulo à Docência (GED). Os salários indiretos foram usados para amenizar a ausência de reajustes salariais.

A reposição inadequada do quadro funcional, utilizando-se do artifício da contratação precária de professores substitutos foi acompanhada do crescimento da produtividade do sistema público, por meio da abertura de turmas no período noturno e do aumento do contingente de alunos em sala de aula.

Este cenário tornou-se ainda mais crítico a partir das sucessivas mudanças na legislação previdenciária do setor público, que induziram a aposentadoria precoce de docentes, sendo que os mais qualificados reforçaram os quadros das instituições privadas. Houve um movimento de transferência de reitores de universidades estaduais e federais para as privadas e de grupos de pesquisa e pós-graduação, assim como do financiamento que eles atraem.

Diante da ação estatal que se desobrigava da adequada manutenção do sistema federal, a saída para as IFES foi a privatização no interior 
das instituições, por meio da disseminação de parcerias entre as universidades públicas e as fundações privadas destinadas à complementação salarial docente $^{20}$ e à oferta de cursos pagos de extensão.

Outra questão relevante diz respeito à extinção da gratuidade nas instituições públicas, que está na agenda governamental desde a Reforma Universitária de 1968. Apesar dos documentos oficiais daquele período terem indicado a necessidade da cobrança de mensalidades, este ponto acabou sendo retirado da legislação final, como produto do consenso e acomodação de interesses divergentes (CARVALHO, 2002).

Na década de 90, novamente volta à baila, por meio das recomendações do Banco Mundial, as propostas de cobrança de mensalidades nas IFES, com a justificativa de garantir maior eficiência e eqüidade ao sistema. Mais uma vez, os atores fizeram pressões políticas no âmbito do Poder Legislativo que impediram que essa sequer fosse levada à votação.

No entanto, as recomendações do Banco Mundial para a cobrança de mensalidades nas instituições públicas, com a justificativa de garantir maior eficiência e eqüidade ao sistema, ainda não foram implementadas. Esta questão polêmica sofre pressões políticas no âmbito do Poder Legislativo que impedem que esta sequer seja levada à votação. ${ }^{21}$

Apesar da correlação de forças entre os interesses públicos e privados tender para os últimos, as associações defensoras dos interesses particulares também acumularam perdas, a partir da diferenciação institucional intra-segmento privado. Até 1997, todos os estabelecimentos particulares de ensino usufruíram imunidade tributária sobre a renda, os serviços e o patrimônio. A partir de então, as instituições passaram a ser classificadas em privadas strito sensu e sem fins lucrativos (confessionais, comunitárias e filantrópicas). As primeiras deixaram de se beneficiar diretamente de recursos públicos e indiretamente da renúncia fiscal, enquanto que as demais permaneceram imunes ou isentas da incidência tributária. A mudança legislativa permitiu ampliar a arrecadação da União (IRPJ, INSS, CSLL, CONFINS) e dos municípios (ISS e IPTU).

Essa ação estatal não interferiu a trajetória expansiva das matrículas particulares nos governos de FHC, principalmente, a partir de 1998, conforme mostram os dados do Gráfico 1. A atuação efetiva do Conselho Nacional de Educação materializou-se na flexibilização na abertura de cursos e instituições.

20 Sobre as fundações privadas nas universidades públicas, consultar: Sguissardi (2002).

21 A extinção da gratuidade nas instituições públicas está na agenda governamental desde a Reforma Universitária de 1968. Apesar de os documentos oficiais terem indicado a necessidade da cobrança de mensalidades, este ponto acabou sendo retirado da legislação final, como produto do consenso e acomodação de interesses divergentes. Carvalho (2002). 
No entanto, é importante salientar que a alternativa privada - exaltada pelo BIRD como solução para a expansão acelerada na oferta de vagas tem encontrado limites estruturais no poder aquisitivo de sua clientela (CORBUCCI, 2002). Ainda mais quando se leva em conta restrições econômicas características dos anos 90, tais como o baixo e oscilante crescimento econômico e suas conseqüências mais perversas, como o desemprego e a queda na renda real média, visualizados nos gráficos 2 e 3 anteriormente apresentados.

A assimetria entre o crescimento da oferta de vagas e a evolução na procura pelas instituições particulares reduziu a relação candidato/vaga de 2,9, em 1995, para 1,6, em 2002. 0 esgotamento da expansão do ensino superior pela via privada fica ainda mais evidente quando se observa o percentual de vagas não preenchidas pelo vestibular nestas instituições. Enquanto em 1998, a proporção já era de $20 \%$ em 2002, as vagas não preenchidas saltam para $37 \%$.

Nesse sentido, é possível concluir que a política pública que privilegia a democratização pela via privada não encontra como principal entrave a oferta insuficiente de vagas, mas a natureza dessas vagas e/ou a capacidade dos candidatos em as ocupar (CORBUCCI, 2002).

A extinção da gratuidade na rede pública estadual e federal apenas tende a agravar o problema dos excedentes às avessas, em outras palavras, a questão não é a ausência de vagas para entrada no ensino superior, mas a escassez de vagas públicas e gratuitas, uma vez que a relação candidato/vaga nestas instituições tem aumentado de forma significativa.

Neste contexto, o programa crédito educativo (FIES) - recomendado exaustivamente pelo Banco Mundial - direcionado aos alunos de baixa renda deixa de ser uma alternativa viável, face à defasagem entre o aumento da taxa de juros do empréstimo e a taxa de crescimento da renda do recém-formado, combinada ao aumento do desemprego na população com diploma de terceiro grau.

Em resumo, a política pública para o ensino superior, principalmente no segundo mandato de FHC, parece indicar maior aproximação com os preceitos neoliberais, sob diversas formas: a visão gerencial e a tentativa de transformar as universidades públicas em organizações sociais; o sucateamento e a disseminação de cursos pagos de extensão em IFES; a atribuição ainda mais intensa à iniciativa privada na expansão de vagas com incentivo para abertura de cursos e instituições; e a adoção dos princípios de avaliação e diferenciação institucional a todo sistema.

No entanto, o meio acadêmico público continuou desempenhando papel central na implementação da política para o setor. A extinção da gratuidade do ensino público foi retirada, novamente, da agenda governamental por pressão exercida no Poder Legislativo. 


\section{Considerações Finais}

É possível concluir que a política para o ensino superior na década de noventa foi permeável às políticas macroeconômicas no que tange à reestruturação da produção e à reforma do Estado. Nesse sentido, a política educacional ficou a reboque das decisões econômicas - nos moldes dos diagnósticos e recomendações dos organismos financeiros transnacionais.

Vale frisar que, apesar das propostas do Banco Mundial constituírem-se em tendência para a maioria dos países latino-americanos, os preceitos neoliberais foram assimilados de forma diferenciada, de acordo com a correlação de forças políticas internas. Em outras palavras, a conjuntura política, a dimensão e a organização do movimento docente e dos estudantes, assim como os blocos no poder em cada um dos países, todos estes elementos foram fundamentais para que as recomendações do Banco resultassem em políticas distintas (CUNHA apud RIBEIRO, 2000).

No caso brasileiro, o aprendizado durante a transição política da ditadura militar ao regime democrático e as conquistas sociais garantidas pela Constituição Federal de 1988, por um lado, e a adesão tardia ao Consenso de Washington, por outro, condicionaram um modo peculiar de inserção na agenda neoliberal.

No que tange ao processo decisório, as diversas iniciativas parciais de reforma do ensino superior foram constantemente debatidas no meio acadêmico e no Poder Legislativo, tanto durante a formulação como ao longo da implementação da política pública para o setor. Os resultados não deixam dúvidas, ainda que o perfil privatista foi o mote do período, o projeto do MARE não foi concretizado face à pressão do movimento docente e de funcionários técnico-administrativos. A extinção da gratuidade retornou à agenda governamental, inspirada na agenda sistêmica, e, novamente, foi rejeitada no Congresso Nacional.

Em suma, corroborando com a hipótese de trabalho, é possível concluir que apesar da proximidade da agenda governamental à agenda sistêmica de cunho neoliberal, a ação dos atores sociais e políticos, nos anos 90, em especial, entre 1995 e 2002, conformaram a implementação, em parte, diferenciada àquela constante dos textos oficiais e das recomendações do Banco Mundial. 


\section{Referências}

AMARAL, N. C. Financiamento da educação superior: estado x mercado. São Paulo: Cortez, 2003.

ANDERSON, P. Balanço do Neoliberalismo. In: GENTILI, Pablo. Pósneoliberalismo: as políticas sociais e o Estado democrático. 5. ed. Rio de Janeiro Paz e Terra, 2000.

BORÓN, A. A sociedade civil depois do dilúvio neoliberal. In: GENTIL, Pablo. Pós-neoliberalismo: as políticas sociais e o Estado democrático. 5. ed. Rio de Janeiro: Paz e Terra, 2000.

CARDOSO DE MELLO, J.M. A contra-revolução liberal-conservadora e a tradição crítica latino-americana. Um prólogo em homenagem a Celso Furtado. In: TAVARES, M. da C.; FIORI, J. L. (Orgs.) Poder e dinheiro: uma economia política da globalização. 3. ed. Petrópolis: Vozes, 1997.

CARVALHO, C. H. A de. Reforma universitária e os mecanismos de incentivo à ex pansão do ensino superior privado no Brasil. (1964-1984). 2002. Dissertação (Mestrado em Economia) - Instituto de Economia, UNICAMP, Campinas, 2002.

CASTRO, J. A. de. O processo de gasto público na área de educação no Brasil: o Ministério da Educação e Cultura nos anos 80. 1997. Tese (doutorado em Economia) - Instituto de Economia, UNICAMP, Campinas, 1997.

COBB, R. W.; ELDER, C. D. Issues and Agendas. In: THEODOULOU, S. Z.; CAHN, M. A. (ed.). Public policy: the essencial readings. New Jersey: Prentice Hall, 1995.

CORBUCCI, P.R Avanços, limites e desafios das Políticas do MEC para a Educação Superior na Década de 1990: ensino de graduação. Texto para Discussão IPEA, n. 869, mar. 2002.

CUNHA, L A. O ensino superior no octênio FHC. Educação e Sociedade, v. 24, n. 82, abr. 2003.

DRAIBE, S. M. A Política social na América Latina: o que ensinam as experiências recentes de reformas? In: DINIZ, E. ; AZEVEDO, S. de. (Org.) Reforma do Estado e democracia no Brasil. Brasília: ENAP, 1997.

. As políticas sociais e o neoliberalismo: reflexões suscitadas pelas experiências latino-americanas. Revista da USP, São Paulo, n. 17, 1993. 
FAGNANI, E. Ajuste econômico e financiamento da política social brasileira: notas sobre o período 1993/98. Economia e Sociedade, n. ํ 13, dez. 1999.

GISI, M. de L Políticas Públicas, Educação e Cidadania. In: ZAINKO, M. A. S, GISI, M.de L. (Orgs.) Políticas e Gestão da Educação Superior. Curitiba: Champagnat: Florianópolis: Insular, 2003.

KINGDON, J. W. Agenda Setting. In: THEODOULOU, S. Z., CAHN, M.A. (ed.). Public Policy: The essencial readings. New Jersey: Prentice Hall, 1995.

MARTINS, C. E. Da Globalização da economia à falência da democracia. Economia e Sociedade, n. o 06, jun. 1996.

RIBEIRO, M. das G M. Políticas para a Educação Superior no Cone Sul: Do autoritarismo ao neoliberalismo. Pró-Posições, v. 11, nº 3, nov. 2000. AMARAL, N. C. Financiamento da Educação Superior: estado x mercado. São Paulo: Cortez, 2003.

SGUISSARDI, V. Fundações Privadas na Universidade Pública. A quem interessam? Avaliação, ano 7, no 26 (4), dez. 2002.

. O desafio da educação superior no Brasil: quais são as perspectivas? Avaliação, v. 5, n. 2, p.16, jun. 2000.

SILVA JÚNIOR, J. dos R; SGUISSARDI, V. Reforma do Estado e reforma da educação superior no Brasil. In: SGUISSARDI, V. (Org). Avaliação universitária em questão: reformas do Estado e da educação superior. Campinas: Autores Associados, 1997.

TÁPIA, J. R. B. A trajetória da política de informática brasileira: (19771991): atores, instituições e estratégias. 1993. Tese (Doutorado em Ciência Política) - IFCH/USP, São Paulo, 1993. 